\title{
MÚSICA, RAÇA E PRECONCEITO \\ NO ENSINO FUNDAMENTAL: \\ NOTAS INICIAIS SOBRE HIERARQUIA DA COR \\ ENTRE ADOLESCENTES
}

\section{Wilma de Nazaré Baía Coelho* Mauro Cezar Coelho**}

\begin{abstract}
$\mathrm{A}$ música, esse amálgama de letra e melodia, compõe a vida da sociedade contemporânea. Ela não somente constitui uma forma de expressão artística, mas também uma modalidade de entretenimento e um ramo da economia, a indústria da música, envolvendo uma legião de profissionais e rendendo dividendos portentosos. Como manifestação artística, a música pode ser entendida como uma criação híbrida que, congregando melodia e poesia, divide-se em gêneros e subgêneros diversos - o erudito (câmera, ópera, sinfônica), o popular (rock, gospel, samba). ${ }^{1}$ Não obstante, no tempo atual, a música, especial-
\end{abstract}

* Professora da Universidade Federal do Pará. E-mail: wilmacoelho@yahoo.com.br *** Professor da Universidade Federal do Pará. E-mail: mauroccoelho@yahoo.com.br

Álvaro Neder discute as implicações do uso do termo música popular. Para ele, a leitura que os musicólogos tendem a realizar, caracterizando-a como uma música com característica de 'sofisticada' organização, gera problemas "definicional-teóricos”. O autor se propõe a compreendê-la em seu dinamismo e sugere que o termo seja entendido por meio de suas relações (Álvaro Neder, "O estudo cultural da música popular brasileira: dois problemas e uma contribuição", Per Musi - Revista Acadêmica de Música, n. 22 (2010), pp. 181-96). Para uma análise dos impasses da música erudita no Brasil, as análises de José E. Martins são sugestivas. Ele destaca as transformações ocorridas no ensino musical no Brasil e aponta o espaço cada vez mais restrito dedicado à música erudita, em razão da crescente e acelerada ascensão da cultura de massa, impulsionada pela indústria cultural (José Eduardo Martins, "A cultura musical erudita na universidade: refúgio, resistência e expectativas", Estudos Avançados, v. 7, 
mente a denominada popular, tem uma função importante na indústria: o consumo massificado e imediato.

Uma dimensão desse aspecto é o que se pretende tratar, isto é, o consumo da música pelos adolescentes ${ }^{2}$ como uma chave para a compreensão desse grupo etário e de uma das dimensões de sua vida: a leitura que fazem da hierarquia da cor e a forma como se percebem nela, perscrutando-se de que forma a preferência manifestada por adolescentes que cursam o ensino fundamental permite entrever a relação que estabelecem com esse significante social brasileiro - a cor.

Mas, por que a música? O trato com o universo adolescente não é fácil. A dificuldade - que fique bem entendido - é se fazer aceito, de modo a poder realizar uma etnografia da adolescência. Por outro lado, a questão, desde a partida, foi a compreensão do quanto a escola contribui para a formulação de visões de mundo. ${ }^{3}$ A música pareceu o caminho por meio do qual se teria acesso às formulações daquele grupo etário, a partir do seu consumo e da identificação com esse ou aquele gênero ou essa ou aquela canção. Sob a inspiração de um conjunto de trabalhos que analisou o lugar ocupado pela música na vida de adolescentes e jovens da periferia de grandes cidades brasileiras, partiu-se da premissa de que a música (entendida como um amálgama de letra e melodia) expressa valores, tradições e posicionamentos.

Supondo-se que a música pode ser percebida por meio da compreensão do conceito de campo, ${ }^{4}$ é possível considerar-se o consumo

n. 18 (1993), pp. 163-81). Ainda sobre a música erudita no Brasil, ver o trabalho de José Miguel Wisnik, "Entre o erudito e o popular", Revista de História, n. 157 (2007), pp. 55-72.

2 Nesse aspecto, fatores biológicos, psicossociais e culturais encontram-se articulados às "questões de gênero, às hierarquias familiares e sociais, bem como à assunção de uma identidade pessoal e social, construída contra o pano de fundo das relações sociais e institucionais" (Maria Cláudia S. Lopes de Oliveira, "Identidade, narrativa e desenvolvimento na adolescência: uma revisão crítica”, Psicologia em Estudo, v. 11, n. 2 (2006), pp. 427-36.

3 Ainda que reconheçamos que se aprende a pensar em muitos e diversificados lugares, assumimos que a escola é o espaço no qual tal aprendizado se dá de forma intencional e sistemática, conforme pontuam os autores destacados aqui: Claudia Davis, Marina M. R. Nunes e Cesar A. A. Nunes, "Metacognição e sucesso escolar: articulando teoria e prática", Cadernos de Pesquisa, v. 35, n. 125 (2005), pp. 205-30.

4 Pierre Bourdieu, O poder simbólico, Rio de Janeiro: Bertrand Brasil, 2010; Pierre Bourdieu, $A$ dominação masculina, Rio de Janeiro: Bertrand Brasil, 2010; Maria Drosila Vasconcelos, "Pierre Bourdieu: a herança sociológica”, Educação \& Sociedade, v. 23, n. 78 (2002), pp. 77-87. 
musical como uma fonte para a reflexão sobre os significados que os adolescentes atribuem àquela hierarquia e como se inserem nela. Esse consumo viabiliza, ainda, a reflexão sobre o impacto que o saber esco$\operatorname{lar}^{5}$ exerce sobre suas visões de mundo e sobre a lógica que organiza as relações sociais que estabelecem entre si.

Uma questão exige esclarecimento. Ela diz respeito à consideração da preferência musical de adolescentes, expressa pela indicação de músicas com as quais se identificam, como meio de análise da visão que estabelecem sobre o mundo e da apropriação que fazem do saber escolar relativo à questão étnico-racial. Sendo a escola um espaço que reúne jovens de origem social diversa, cabe a consideração sobre o estatuto da música como meio de expressão do que pensam e como fonte a partir da qual se podem elaborar certas generalizações.

Desde a difusão dos meios de comunicação e da popularização do acesso à música (tanto por meios legais, quanto por meio da pirataria), a preferência musical deixou de ser um índice concreto de distinção social. ${ }^{6}$ Segundo os dados reunidos, as preferências por essa ou aquela música não são determinadas ou condicionadas pela situação social do adolescente. Um exemplo disso pode ser percebido em relação ao gênero brega ${ }^{7}$ e à variedade de subgêneros e "correntes" desse movimento musical no

\footnotetext{
5 Cf. Vera Vanessa Vademarin, "O discurso pedagógico como forma de transmissão do conhecimento", Cadernos Cedes, v. 19, n. 44 (1998), pp. 73-84; Ana Maria Ferreira da Costa Monteiro, "Professores: entre saberes e práticas", Educação \& Sociedade, v. 22, n. 74 (2001), pp.121-42; Ana Maria Ferreira da Costa Monteiro, "Entre o estranho e o familiar: o uso de analogias no ensino de história”, Cadernos Cedes, v. 25, n. 67 (2005), pp. 333-47; Oldimar Pontes Cardoso, "Representações dos professores sobre saber histórico escolar", Cadernos de Pesquisa, v. 37, n. 130 (2007), pp. 209-26; Márcia Cristina de Souza Pugas e Ana Paula Batalha Ramos, "Saberes escolares no ensino de História das séries iniciais: uma aproximação a partir da epistemologia social escolar", 31 a Reunião Anual da ANPED, 2008.

6 Ver Bourdieu, O poder simbólico.

7 Para Lydia Barros, o "brega paraense expõe recorrências significativas na música eletrônica que explodiu nos Estados Unidos nos anos 1990, baseada em estilos como o house e o tecno; a música que encontrou tradução na cultura rave inglesa e que ganhou releituras pelo mundo. A utilização dos teclados, a mistura da disc music com bateria eletrônica (o house)." (Lydia Barros, "Tecnobrega, entre o apagamento e o culto", Revista Contemporânea, n. 12 (2009), p. 6279). Ver também: Paulo Murilo Guerreiro do Amaral, "Estigma e cosmopolitismo na constituição de uma música popular urbana de periferia: etnografia da produção do tecnobrega em Belém do Pará" (Tese de Doutorado, Universidade Federal do Rio Grande do Sul, 2009). Sobre música na região Norte, ver Tony Leão da Costa, "Música do Norte: intelectuais, artistas populares, tradição e modernidade na formação da 'MPB' no Pará (anos 1960 e 1970)"
} 
Pará. ${ }^{8}$ Originalmente um gênero popular, restrito à periferia da cidade de Belém, ele passou a ser consumido por todas as camadas sociais.

A música detém um caráter simbólico que parece diluir as fronteiras sociais, pelo menos no que diz respeito a certos aspectos da visão de mundo construída. Não obstante, ela também se presta ao estabelecimento de identificações, em especial entre adolescentes, como é o caso das bandas reconhecidas como emo-pop, ${ }^{9}$ especialmente consumidas pelos adolescentes que se identificam como emos. Isso é o considerar as preferências musicais compartilhadas como uma expressão da identidade $^{10}$ adolescente, sem prejuízo de sua diversidade.

(Dissertação de Mestrado, Universidade Federal do Pará, 2008), p. 256; Andrey Faro de Lima, "É a festa das aparelhagens! Performances culturais e discursos sociais" (Dissertação de Mestrado, Universidade Federal do Pará, 2008), p. 136.

8 Entre as diversas "correntes" desse movimento, há o tecnomelody, subgênero que participa do desenvolvimento e da diversificação que o brega experimenta no mercado musical paraense. Ele passou a ser popularizado em 2009, com características do tecnobrega (combinação de brega com a percussão eletrônica) e do lirismo romântico do brega tradicional (ritmo musical em que há influência da música romântica combinada com a guitarrada). Cf.: José Augusto Mendes Lobato, "O grito difuso da periferia: hibridismo e tensões entre o popular e o massivo do brega paraense", Comtempo - Revista do Programa de Pós-Graduação da Faculdade Cásper Líbero, v. 2, n. 2 (2010), pp. 1-11; Paulo Murilo Guerreiro do Amaral, "Estigma e cosmopolitismo local: considerações sobre uma estética legitimadora do tecnobrega em Belém do Pará", 2009. <http:// www.bregapop.com/home/index.php?option=com_content\&task=view\&id=4951\&Itemid=835>, acessado em 06/03/2012. Sobre a temática, cf. ainda: Antônio Maurício Dias da Costa, Festa na cidade: o circuito bregueiro de Belém do Pará, Belém: EDUEPA, 2009; Ana Paula de Vilhena, "Sociabilidade e consumo juvenil nas festas de aparelhagem de Belém do Pará", in Anais do XI Congresso Luso-Afro-Brasileiro de Ciências Sociais (Salvador, Universidade Federal da Bahia, 2011, pp. 1-17), pesquisa etnográfica nas festas de aparelhagem de Belém, em que pontua como os jovens frequentadores pautam suas práticas de consumo e sociabilidade e identifica a formação de grupos, os padrões de indumentária, as noções de territorialidade e os significados atribuídos a estes aspectos. Em espaço escolar, constatamos alguns aspectos diferentes entre adolescentes, abordados no corpo do artigo.

9 A identificação de um grupo como emo pop deve ser entendida como pertencente a múltiplas identidades juvenis contemporâneas, denominadas de tribos juvenis (como a dos emos), com estudos e análises associando a essa tribo grande emotividade e produção de um visual específico (uso de uma longa franja pelos meninos, característica-chave do "estilo" emo). Outra tribo urbana é a dos chamados emocore, que se caracteriza como "herança maldita, ou o filho bastardo do Punk". Sobre o fenômeno das tribos urbanas e as consequências comportamentais dos atores sociais, percebe-se que os sujeitos contemporâneos fazem parte de uma sociedade definida por um inconsciente coletivo governante, encarado a partir da sociedade de consumo, da ética da estética corporal e da autonomia da identificação com o outro apenas por atitudes. Cf.: Isabela Fonseca Cardoza, "A sociedade pós-moderna e o fenômeno das tribos urbanas", Lato \& Sensu, v. 4, n. 1 (2003),pp. 3-5; Elisabete Maria Garbin, “Cultur@s juvenis, identid@des e internet: questões atuais”, Revista Brasileira de Educação, n. 23 (2003), pp. 119-35.

${ }^{10}$ Stuart Hall, A identidade cultural na pós-modernidade, Rio de Janeiro: DP\&A, 2005. 
A reflexão apresentada a seguir é resultado da análise preliminar de dados de uma pesquisa em andamento. Para este artigo, analisam-se os dados recolhidos em uma amostra constituída de 222 estudantes da faixa etária de nove a quinze anos, do turno matutino de uma escola privada de ensino fundamental da cidade de Belém. As considerações a seguir são resultado desse contato preliminar, em meio ao levantamento de dados em outras escolas.

\section{A problemática}

Durante o final dos anos 1970 e por toda a década de 1980, as estruturas sociais e educacionais brasileiras tornaram-se objeto de análises de diversos intelectuais, especialmente do campo das humanidades. Os processos de transição democrática pelos quais passava o país foram determinantes para a emergência desses debates. Os discursos sobre educação manifestavam perspectivas diversas sobre o lugar da escola. Os de maior repercussão defendiam a escola como um instrumento fundamental para o processo de (re)democratização da nação. Desse modo, o discurso pedagógico produzido naquele período esteve voltado para o enfrentamento da crise do modelo social, político e educacional implantado, a partir de 1964, pelos governos autoritários, ${ }^{11}$ visto como promotor da exclusão social, tornada evidente pelo censo demográfico de 1976.

De acordo com a crítica emergente nos anos 1980, as décadas em que o Brasil esteve sob a égide da ditadura militar assistiram ao assalto do universo educacional pelas teorias do chamado Capital Humano e do Tecnicismo. ${ }^{12}$ Ambas apontavam a necessidade de um planejamento detalhado das atividades escolares, relativo tanto à administração escolar quanto aos procedimentos pedagógicos. Planejar e executar, de acordo com técnicas e modelos de reconhecida eficiência, satisfazia ao anseio

\footnotetext{
11 José Willington Germano, Estado militar e educação no Brasil (1964-1985), São Paulo: Cortez, 2005.

12 Dermeval Saviani, "Competência política e compromisso técnico ou o pomo da discórdia e o fruto proibido", Educação \& Sociedade, n. 15 (1983), pp. 111-43.
} 
daquele aporte de formar agentes produtivos, aptos para desempenhar funções no mundo do trabalho, tornando-se úteis ao capital industrial.

Desde o final da década de 1970, num crescente que alcançou seu ponto máximo na segunda metade da década seguinte, formularam-se críticas aos modelos consubstanciados nas obras referidas. Uma parte delas foi pensada com base na reflexão de Pierre Bourdieu e Jean-Claude Passeron, ${ }^{13}$ que tinham o universo educacional francês como objeto e propunham outra forma de analisar a escola e o lugar ocupado pelos seus agentes. Segundo a perspectiva que adotaram, a escola contribuiria para a reprodução das estruturas sociais. Assim, diferenças sociais ver-se-iam repetidas no universo escolar. Para esses autores, a escola seria um campo de possível reprodução da cultura dominante, o instrumento de imposição do arbítrio cultural de um grupo e/ou classe social sobre os demais, mas não irremediavelmente imobilizado. Sua ação pedagógica se limitaria a passar adiante, como universais, valores próprios de um único grupo. Sob essa assertiva, o sistema escolar contribuiria para ratificar, sancionar e transformar em mérito escolar heranças culturais transmitidas pela estrutura familiar. ${ }^{14}$ Assim, esses autores romperam com as explicações fundadas em aptidões naturais e individuais, ensejando de modo precursor a crítica do mito do "dom", no sentido de disposições inatas.

As teses de Pierre Bourdieu - especialmente as compartilhadas com Jean-Claude Passeron em obra importante como A reprodução — não estiveram infensas a críticas. ${ }^{15}$ Uma delas foi elaborada por Henry Giroux, ${ }^{16}$ negando a condição de instituição reprodutora atribuída à escola. Para ele, a escola também produzia e, em função desse posicionamento, elaborou uma reflexão que assumia as possibilidades do ensino e da aprendizagem como instrumento de emancipação do homem. Outra crítica, formulada por Annick Percheron, ${ }^{17}$ sublinhava que a trajetória do grupo

13 Pierre Bourdieu e Jean-Claude Passeron, A reprodução: elementos para uma teoria do sistema de ensino, Rio de Janeiro: Francisco Alves, 2008.

14 Bourdieu, A dominação masculina.

15 Vasconcelos, "Pierre Bourdieu".

16 Henry Giroux, "O pós-modernismo e o discurso da crítica educacional: novas políticas em educação", in Tomaz Tadeu da Silva (org.), Teoria educacional crítica em tempos pós-modernos (Porto Alegre: Artes Médicas, 1993).

17 Annick Percheron, "Stratégies éducatives, normes éducatives et classes sociales", in F. Mariet (org.), L'enfant, la famille et l'école (Paris: ESF, 1981). 
familiar, o nível educacional de cada indivíduo, o ambiente em que se vive (se rural ou urbano), a postura familiar (se mais ou menos conservadora, se religiosa ou não) e as múltiplas variações desses aspectos contavam tanto quanto a questão de classe na atuação social dos agentes e na forma como apreendiam o que lhes era apresentado. ${ }^{18}$

As considerações de Bourdieu e de seus críticos mantiveram o lugar da escola - como espaço de contribuição à reprodução ou à transformação das estruturas sociais - em discussão. Na nascente (re)democratização política, a escola brasileira tem sido vista como território de formação do cidadão crítico, ${ }^{19}$ e o seu caráter de instância formadora e transformadora vem sendo enfatizado, seja pelo pensamento educacional, seja pelo senso comum. As reflexões nesse sentido raramente concebem a escola como instância reprodutora de preconceitos - à exceção de alguns trabalhos relativos à questão étnica e racial no universo educacional. ${ }^{20}$ Cabe, no entanto, investigar os desdobramentos que a formação do cidadão crítico acarreta no estabelecimento de sociabilidades, ${ }^{21}$

18 Para outras críticas à obra citada, ver os trabalhos de Bernard Charlot, Da relação ao saber: elementos para uma teoria, Porto Alegre: Artmed, 2000; Bernard Lahire, Homem plural: os determinantes da ação, Petrópolis, Rio de Janeiro: Vozes, 2002; Bernard Lahire, "Crenças coletivas e desigualdades culturais", Educação \& Sociedade, v. 24, n. 84 (2003), pp. 983-95; Bernard Lahire, "Reprodução ou prolongamento críticos?", Educação \& Sociedade, v. 23, n. 78 (2002), pp. 37-55.

19 Para uma crítica aos encaminhamentos dados à formação para a cidadania, ver: Wilma de Nazaré Baía Coelho e Mauro Cezar Coelho, "O improviso em sala de aula: a prática docente em perspectiva”, in Wilma N. B. Coelho e Mauro C. Coelho (orgs.), Raça, cor e diferença: $a$ escola e a diversidade (Belo Horizonte: Mazza, 2009), pp.104-23.

20 Entre os quais, destacamos: Nilma Lino Gomes, "Diversidade étnica racial, inclusão e equidade na educação brasileira: desafios, políticas e práticas", RBPAE, v. 21, n. 1 (2011), pp. 109-21; Wilma Nazaré Baía Coelho, "Só de corpo presente: o silêncio tácito sobre cor e relações raciais na formação de professores no estado do Pará", Revista Brasileira de Educação, v. 12, n. 34 (2007), pp. 39-56; Ana Lúcia Valente, “Ação afirmativa, relações raciais e educação básica", Revista Brasileira de Educação, n. 28 (2005), pp. 62-77.

21 Destacamos, a seguir, três trabalhos que dão conta da discussão sobre sociabilidades e hierarquias: Jesus Maria Sousa, "O olhar etnográfico da escola perante a diversidade cultural", Revista de Psicologia Social Institucional, v. 2, n. 1 (2000), pp. 107-20, que aborda as questões de sociabilidade juvenil entre homossexuais e heterossexuais de São Paulo, a partir das diferenças de cor/raça, classe, gênero e sexualidade; Paulo Meksenas, "Alegoria do duelo e os conflitos escolares", Educação \& Sociedade, v. 30, n. 106 (2009), pp. 111-29, acerca das sociabilidades escolares, por meio da análise dos conflitos e do uso da violência entre estudantes; Nicelma Brito Soares e Wilma de Nazaré Baía Coelho, "Pertencimento racial e relações sociais estabelecidas no espaço escola", Instrumento, v. 13 (2011), pp. 135-44, sobre as relações possíveis entre as hierarquias escolares e as hierarquias da cor. 
especialmente naquelas que não são engendradas ou geridas pelo ambiente escolar - como o consumo musical, por exemplo. A questão que se coloca é se tal formação tem resultado na apropriação de valores, a partir da escola, que interferem nas dinâmicas de sociabilidade juvenil.

Uma última questão deve ser apresentada. A investigação sobre o modo pelo qual os adolescentes percebem a hierarquia racial brasileira e a vivenciam exige o manuseio das categorias de discriminação e preconceito. Não se tem aqui o objetivo de arrolar as representações que lhe são relacionadas, mas o de tentar entendê-las como resultado de um contexto presente no universo educacional. Por meio desse movimento, pretende-se participar do debate sobre a dimensão que a reprodução e a transformação assumem no ambiente escolar. Diante desse propósito, as formulações teóricas nas quais a investigação procurou pautar-se conceituam o racismo como uma relação de poder alicerçada pela ideia de raça ${ }^{22}$ que, por meio do preconceito e da discriminação, acaba por fundamentar diálogos assimétricos entre os grupos sociais, com referência em atributos fenotípicos. ${ }^{23}$ Trata-se de um fenômeno histórico, ${ }^{24}$

22 O termo "raça" é aqui empregado com o sentido de "raça social", conforme explicitado por Antônio Sérgio Alfredo Guimarães, isto é, não se trata de um dado biológico, mas de "construtos sociais, formas de identidade baseadas numa ideia biológica errônea, mas eficaz socialmente, para construir, manter e reproduzir diferenças e privilégios". Para esse autor, se a existência de raças humanas não encontra qualquer comprovação no bojo das ciências biológicas, elas são, contudo "plenamente existentes no mundo social, produtos de formas de classificar e de identificar que orientam as ações dos seres humanos" (Antônio Sérgio Alfredo Guimarães, "Raça e os estudos de relações raciais no Brasil”, Novos Estudos Cebrap, n. 54 (1999), pp.147-56) Cf. também: Antônio Sérgio Alfredo Guimarães, Classes, raças e democracia. São Paulo: Fundação de Apoio à Universidade de São Paulo: Editora 34, 2002; Antônio Sérgio Alfredo Guimarães, "Como trabalhar com 'raça' em sociologia", Educação e Pesquisa, v. 29, n. 1 (2003), pp. 93-108. Considerações sugestivas sobre esse termo foram feitas por outros autores, como: Nilma Lino Gomes, "Alguns termos e conceitos presentes no debate sobre relações raciais do Brasil: uma breve discussão" in Educação anti-racista: caminhos abertos pela Lei Federal $n^{\circ} 10.639 /$ 03 (Brasília: Ministério da Educação, Secretaria Continuada, Alfabetização e Diversidade, 2005), pp. 39-62; e Lilia Moritz Schwarcz, "Racismo no Brasil: quando inclusão combina com exclusão", in André Botelho e Lilia Moritz Schwarcz (orgs.), Agenda Brasil: temas de uma sociedade em mudança (São Paulo: Companhia das Letras, 2011), pp.430-43.

23 Antônio Sérgio Alfredo Guimarães, "Democracia racial", Tempo Social, v. 18, n. 2 (2006), pp. 269-87; Antônio Sérgio Alfredo Guimarães, "Preconceito de cor e racismo no Brasil", Revista de Antropologia, v. 24, n. 1 (2004), pp. 10-43; Lourdes Bandeira e Analía Soria Batista, "Preconceito e discriminação como expressões de violência", Revista Estudos Feministas, v. 10, n. 1 (2002), pp. 119-41; Eliane dos Santos Cavalleiro (org.), Racismo e antiracismo na educação: repensando nossa escola (São Paulo: Summus, 2001).

24 Embora a ideia seja trabalhada em várias obras, uma das principais encontra-se no livro de 
constituído a partir das desigualdades que formaram a sociedade brasileira. O racismo, nesse sentido, é um instrumento de dominação, tanto simbólica quanto material, pois tem seus desdobramentos ideológicos e culturais, bem como sociais e econômicos.

\section{Os agentes}

Um dos grandes desafios da pesquisa em educação é compreender os agentes e as práticas escolares, de modo a desvendar os processos por que passa a escola no tempo presente. Há alguns anos, a literatura educacional tem sido questionada, diante das cobranças, da sociedade civil organizada e do Estado, por resultados que encaminhem soluções para os problemas da educação brasileira. Em que pese a importância dos dados disponibilizados por alguns dos instrumentos de avaliação criados pelos governos nas últimas décadas, ${ }^{25}$ uma lacuna permanece: de

Florestan Fernandes, A integração do negro na sociedade de classe, São Paulo: Dominius, 1965, 2 v. Ver também: Kabengele Munanga, "O racismo no mundo contemporâneo", Cadernos Penesb, v. 2, (2000), pp. 31-44; Lilia Moritz Schwarcz, O espetáculo das raças: cientistas, instituições e questão racial no Brasil - 1870-1930, São Paulo: Companhia das Letras, 2007; Antônio Sérgio Alfredo Guimarães e Lynn Huntley (orgs.), Tirando a máscara: ensaios sobre o racismo no Brasil (São Paulo: Paz e Terra, 2000); Edward Eric Telles, Racismo à brasileira: uma nova perspectiva sociológica, Rio de Janeiro: Relume Dumará/Fundação Ford, 2003; Lilia Moritz Schwarcz, Racismo no Brasil, São Paulo: PubliFolha, 2001; Antônio Sérgio Alfredo Guimarães, Racismo e anti-racismo no Brasil, São Paulo: Editora 34, 2005.

25 Temos, como avaliação da educação básica brasileira, o Sistema Nacional de Avaliação da Educação Básica (SAEB), implantado em 1990 e coordenado pelo Instituto Nacional de Estudos e Pesquisas Educacionais (INEP), que realiza duas avaliações: a Avaliação Nacional da Educação Básica (ANEB), que abrange de maneira amostral os estudantes das redes públicas e privadas do país, localizados em área rural e urbana, matriculados no $5^{\circ}$ e $9^{\circ}$ anos do ensino fundamental e no $3^{\circ}$ ano do ensino médio; e a Avaliação Nacional do Rendimento Escolar (ANRESC), que é aplicada censitariamente a alunos de $5^{\circ}$ e $9^{\circ}$ anos do ensino fundamental público, nas redes estaduais, municipais e federais, de área rural e urbana, em escolas que tenham no mínimo 20 alunos matriculados na série avaliada. Nesse estrato, a prova recebe o nome de Prova Brasil e oferece resultados por escola, município, Unidade da Federação e país, que são utilizados no cálculo do Índice de Desenvolvimento da Educação Básica (IDEB), criado em 2007 para medir a qualidade de cada escola e de cada rede de ensino. As avaliações que compõem o SAEB são realizadas a cada dois anos, quando são aplicadas provas de Língua Portuguesa e Matemática, além de questionários socioeconômicos, aos alunos participantes e à comunidade escolar. Há também o Exame Nacional do Ensino Médio (ENEM), utilizado como forma de seleção unificada nos processos seletivos das universidades públicas federais. Cf.: Elba Siqueira de Sá Barreto. "Avaliação na educação básica entre dois modelos", Educação \& Sociedade, v. 22, n. 75 (2011), pp. 48-66; Dados do INEP em: <http://provabrasil.inep.gov.br/ >; Portal do MEC em: <http://portal.mec.gov.br>. 
modo geral, tais dados não encaminham uma compreensão da escola a partir dos processos concretamente vividos por ela e fornecem um quadro quase estático da situação escolar.

A compreensão do universo escolar demanda a investigação dos agentes escolares dentro e fora da escola. Os ambientes de formação dos profissionais de educação, suas trajetórias de vida, as atuações dos seus órgãos representativos e as representações que formulam sobre a profissão e sobre a própria prática profissional têm sido estudados, ${ }^{26}$ com vistas a apurar o quanto essa dimensão é importante para a compreensão do espaço escolar. Já no que tange ao universo infantil e adolescente, são poucas os estudos que se debruçam sobre outras dimensões que não os processos de ensino e aprendizagem e as trajetórias escolares e seus entraves (reprovação, retenção e evasão, por exemplo). Daí ter-se optado por tratar de uma dimensão que envolve as formas de socialização entre adolescentes e podem dar pistas sobre as formulações que constroem e a relação que mantêm com os processos vividos na escola.

Desde a promulgação das políticas que pautam uma nova perspectiva para a educação básica no que tange ao trato com a memória histórica brasileira - marcadamente o abandono de uma perspectiva eurocêntrica e a inclusão de agentes históricos tradicionalmente desprezados pelas construções narrativas sobre o passado brasileiro -

\footnotetext{
${ }^{26}$ Cf.: José Carlos Libâneo e Selma Garrido Pimenta, "Formação de profissionais de educação: visão crítica e perspectiva de mudanças", Educação \& Sociedade, v. 20, n. 68 (1999), pp. 239-77; Antônio J. Severino, "Educação, trabalho e cidadania: a educação brasileira e o desafio da formação humana no atual cenário histórico", Perspectiva, v. 14, n. 2 (2000), pp. 65-71; Terezinha Azerêdo Rios, "A escola inclusiva está incluindo o professor? Inclusão requer condições - do professor e do contexto", Presente! Revista de Educação, v. 52, (2006), pp. 36-8; Terezinha Azerêdo Rios, "Professores: autores e atores nos dizeres da escola: a contribuição da reflexão filosófica", in Cleide Almeida, Marcos Antonio Lorieri, Antonio Joaquim Severino (orgs.), Perspectivas da filosofia da educação (São Paulo: Cortez, 2011), pp. 208-21; I. P. A. Veiga. "A formação dos profissionais de educação no contexto da inovação pedagógica", Linhas Críticas, v. 7, n. 12 (2001), pp. 5-22; I. P. A. Veiga, "A trajetória profissional e a construção do docente universitário", in Mary Rangel (org.), Educação superior: avanços e práticas (Niterói: Intertexto, 2010), pp. 15-34; Wilma de Nazaré Baía Coelho, Educação, história e problemas: cor e preconceito em discussão, Belo Horizonte: Edições Mazza, 2012; Wilma de Nazaré Baía Coelho e Mauro Cezar Coelho (orgs.), Trajetórias da diversidade na educação: formação, patrimônio e identidade (São Paulo: Livraria da Física, 2012).
} 
verifica-se um relevante número de estudos sobre os impactos da lei. ${ }^{27}$ Sem prejuízo das importantes contribuições que trazem à discussão sobre os desdobramentos daquelas políticas no âmbito escolar, percorrem, não raras vezes, os mesmos caminhos dos estudos consagrados sobre educação: as políticas públicas, a formação docente, as práticas pedagógicas adotadas, entre outros recortes temáticos.

Alguns trabalhos buscam compreender o universo adolescente fora do espaço escolar e, eventualmente, relacionar as formas de identificação e as visões de mundo formuladas por eles aos processos que vivenciam na escola. Dentre eles, destacam-se os que assumem a música como chave para a compreensão do universo juvenil/jovem e perscrutam os processos de identificação intermediados pela música ${ }^{28} \mathrm{e}$ as formas de socialização engendradas a partir das relações estabelecidas com determinado gênero musical. ${ }^{29}$

Todavia, esses estudos tratam, de modo geral, da relação que jovens da periferia de grandes cidades do Centro-Sul travam com a música (e a partir dela) e dizem respeito a conformações sociais que, a despeito do imenso grupo populacional de que se ocupam, restringem-se a

${ }^{27}$ Entre elas a de Jair Santana, “A Lei n 10.639/03 e o ensino de artes nas séries iniciais: políticas afirmativas e folclorização racista” (Tese de Doutorado, Universidade Federal do Paraná, 2010), p. 250; R. J. Souza, "Suscitando debates sob a ótica da Lei n 10.639/03: história antiga sem África", Seminário de Pesquisa de Pós-Graduação em História da UFRJ-Diálogos e Aproximações, Rio de Janeiro, 2008.

28 António Concorda Contador, “A música e o processo de identificação dos jovens negros portugueses", Sociologia, n. 36 (2001), pp. 109-20; Olívia Maria Gomes da Cunha, "Bonde do mal: notas sobre território, cor, violência e juventude numa favela do subúrbio carioca", in Yvonne Maggie e Claudia Barcellos Rezende (orgs.), Raça como retórica: a construção da diferença (Rio de Janeiro: Civilização Brasileira, 2002), pp. 83-154; Ari Lima, "Funkeiros, timbaleiros e pagodeiros: notas sobre juventude e música negra na cidade de Salvador", $C a$ dernos Cedes, v. 22, n. 57 (2002), pp. 77-96; Viviane Melo de Mendonça Magro, “Adolescentes como autores de si próprios: cotidiano, educação e o hip hop", Cadernos Cedes, v. 22, n. 57 (2002), pp. 63-75.

29 Maria Rita Kehl, "Radicais, raciais, racionais: a grande fratria do rap na periferia de São Paulo", São Paulo em Perspectiva, v. 13, n. 3 (1999), pp. 95-106; Juarez Dayrell, "O rap e o funk na socialização da juventude", Educação e Pesquisa, v. 28, n. 1 (2002), pp. 117-36; Jaison Hinkel e Kátia Maheirie, "Rap - rimas afetivas da periferia: reflexões na perspectiva sóciohistórica", Psicologia \& Sociedade, v. 19, n. esp. 2 (2007), pp. 90-9, Carlos Eduardo Pimentel, Valdiney Veloso Gouveia e Tatiana Cristina Vasconcelos, "Preferência musical, atitudes e comportamentos anti-sociais entre estudantes adolescentes: um estudo correlacional", Estudos de Psicologia, v. 22, n. 4 (2005), pp. 403-13; Bruno Zeni, "O negro drama do rap: entre a lei do cão e a lei da selva”, Estudos Avançados, v. 18, n. 50 (2004), pp. 225-41. 
certas conformações sócio-históricas. Algo muito diverso ocorre em áreas com tardio desenvolvimento industrial, com trajetórias distintas e distantes daquelas vividas no Centro-Sul e mesmo em algumas localidades do Nordeste, como a Bahia (Salvador, particularmente). A cidade de Belém, capital do Estado do Pará, sintetiza muito bem essas distinções.

Belém não é infensa às vicissitudes impostas pelos processos de concentração de renda (e a consequente geração de desigualdades) vividos por outras cidades brasileiras. Ela também é demarcada por diferenças, com seus bairros nobres e suas periferias. Estas últimas, no entanto, possuem um desenho particular. São denominadas muitas vezes de baixadas. Não constituem, exclusivamente, bairros ou configurações que denominam uma conformação urbana e social, como favela ou comunidade, mas certas áreas dentro de um bairro. Mesmo a denominação de bairro periférico não assume, em Belém, a conotação de área distante, longe do centro. A periferia é percebida, muito mais, como um espaço pouco assistido pelo poder público, formado pela ocupação de espaços vazios e suscetíveis aos alagamentos constantes, em decorrência das chuvas que acometem a cidade nos meses de janeiro a junho.

A periferia belenense aguarda estudos que the tracem um perfil mais acurado. A escola selecionada para a pesquisa, da qual apresentase aqui uma parte, localiza-se em um bairro considerado periférico, o Guamá, que pertence a uma área mais ampla, definida pela prefeitura como o distrito do Guamá d'Água, e compreende parte dos bairros do Marco, de São Braz, do Guamá (que dá nome ao distrito), da Cremação, de Batista Campos, do Jurunas e da Cidade Velha, e os bairros da Terra Firme, de Canudos e da Condor. Em termos populacionais, o distrito do Guamá é o maior de Belém, com 349.535 habitantes, 182.550 mulheres e 166.985 homens, segundo dados do censo de 2000 , correspondendo a $27 \%$ da população total da cidade. Possuía, então, 75.906 domicílios que correspondiam a $25 \%$ dos domicílios de todo o município. ${ }^{30}$

Conformado, em larga medida, a partir da invasão de terras da União, pertencentes a diversas instituições situadas nas proximidades, o bairro do Guamá se localiza na Bacia do Tucunduba, em área próxima ao

30 Informações disponíveis no site da Prefeitura de Belém: <http://www.belem.pa.gov.br.>. 
centro da cidade, e possuía, em 2000, 102.000 habitantes, segundo estudos circunstanciados. ${ }^{31}$ A renda média familiar era, àquela altura, de $\mathrm{R} \$ 555,24$ e a renda média pessoal de $\mathrm{R} \$ 300,00$ — ambas inferiores aos índices médios da cidade, respectivamente, $\mathrm{R} \$ 859,89$ e R \$ 360,00. Desde aquele ano, foi objeto de iniciativas de urbanização que não foram suficientes para alterar sua situação, pois continua sofrendo com problemas típicos das grandes cidades, conforme documentam as conversas com os agentes da pesquisa: alto índice de violência, falta de serviços públicos e infraestrutura urbana precária. Atualmente, conta com 27 estabelecimentos de ensino: 13 escolas públicas e 12 escolas privadas de educação básica e dois centros públicos de ensino técnico. O quadro depreendido do censo de 2000 pode ser entrevisto ainda hoje no perfil socioeconômico dos alunos que frequentam esses estabelecimentos.

Com vistas a estabelecer um quadro amplo da oferta da educação na cidade, foram selecionadas três escolas de ensino fundamental uma escola pública federal, uma pública estadual e uma escola privada —, localizadas na mesma área da cidade, de modo a garantir que os alunos investigados compartilhassem formas de socialização fora do ambiente escolar. Assim, a escola pública estadual e a escola privada encontram-se no mesmo bairro, distantes algumas quadras; e a escola federal, em bairro contíguo.

O presente estudo se restringe a uma escola em que estão matriculados cerca de 1.480 alunos, 502 do segundo ciclo do ensino fundamental, dos quais foram selecionados $222(15 \%)$, entre os do sexto ao nono ano, à razão de duas turmas por ano/série, num total de oito turmas. Com vistas a identificar os parâmetros de consumo musical dos escolares, optou-se pela utilização de um questionário, composto de oito perguntas, cuja aplicação foi realizada com acompanhamento, de modo que os alunos pudessem satisfazer eventuais dúvidas. Ao longo da análise, considerou-se a situação de aplicação. ${ }^{32}$

\footnotetext{
31 Ver, por exemplo, Maria José de Souza Barbosa, Maria Elvira Rocha de Sá, Armando Lírio de Souza, Cleidiane do O. S. dos Santos e Lúcia Pinho dos Santos, Estudo de caso: Tucunduba: urbanização do igarapé Tucunduba, gestão de rios urbanos - Belém-Pará, Belém: UFPA, 2003.

32 Sobre isso, ver Alice Pereira Xavier, "Uma visão antropológica da aplicação de questionários na pesquisa em educação”, Educar em Revista, n. 44 (2012), pp. 293-307.
} 
O universo pesquisado se distribuiu pelas variáveis de caracterização apresentadas na Tabela 1.

Tabela 1 - Identificação do universo pesquisado

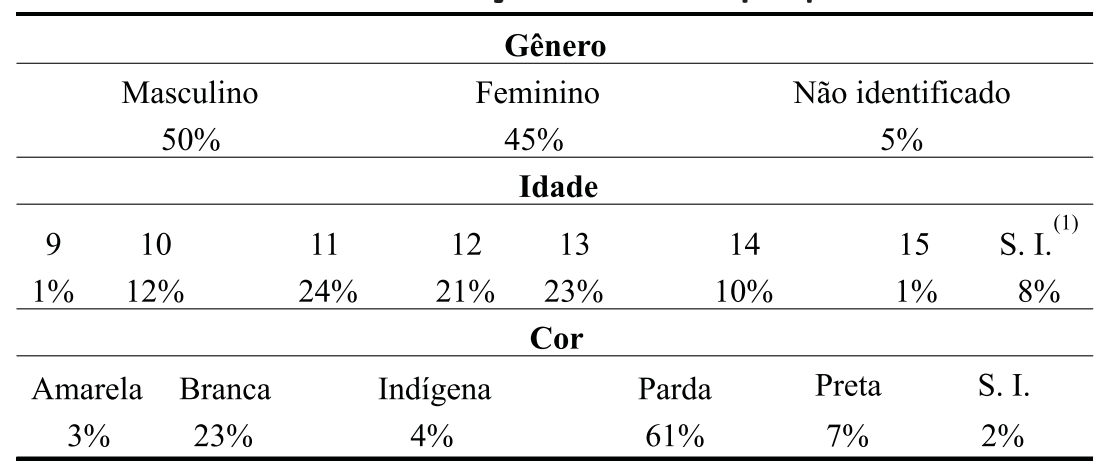

Fonte: Questionário aplicado ao universo pesquisado.

Nota: ${ }^{(1)}$ S. I. = Sem identificação

Com relação à situação socioecômica, a renda familiar de 88,55\% dos escolares era de um a cinco salários mínimos, e a de pouco mais de $11 \%$, de até doze salários mínimos.

Os discentes afirmaram que leem jornais diariamente, em especial as seções de variedades, de registros policiais e de roteiros culturais. Pouco acima de metade do grupo (51\%) afirmou ser leitor assíduo, consumindo doze livros/ano (um percentual muito superior à média nacional e à média da região Norte), ${ }^{33}$ romances, thrillers policiais e comédias. A imensa maioria $(88,55 \%)$ garantiu manter-se conectada à rede mundial de computadores, em grande parte para o lazer, visitando, principalmente, as chamadas "páginas pessoais".

Nossas suspeitas sobre o consumo de músicas entre adolescentes foram confirmadas pelos dados levantados. Quase todo o universo pesquisado $(93,25 \%)$ declarou consumir música diariamente, como se

${ }_{33}$ Cf. notícia publicada pelo Ministério da Cultura em $<$ http://www.cultura.gov.br/site $>$, acessado em 10/08/2011. 
depreende da Tabela 2, e um contingente expressivo (56,31\%) afirmou ouvir pela manhã, à tarde e à noite.

Tabela 2 - Frequência de consumo musical do universo pesquisado

\begin{tabular}{lr}
\hline Período & \% \\
\hline Diuturnamente & 56,31 \\
Um horário no dia & 15,32 \\
Dois horários no dia & 21,62 \\
Semanalmente & 5,4 \\
Quinzenalmente & 0,45 \\
Mensalmente & 0,45 \\
Não respondeu & 0,45 \\
\hline
\end{tabular}

Fonte: Questionário aplicado ao universo pesquisado.

Os dados evidenciaram, ainda, um elemento na relação dos adolescentes com a música: ela não se presta, necessariamente, à fruição, como mostra a Tabela 3.

Tabela 3 - Significados atribuídos ao ato de ouvir música

\begin{tabular}{lc}
\hline Significado & \% \\
\hline Relaxamento & 16 \\
Alegria & 11 \\
Tranquilidade & 8 \\
Bem-estar & 5 \\
Animação & 3 \\
Cultura & 3 \\
Felicidade & 3 \\
Paz & 3 \\
Reflexão & 3 \\
Diversão & 2 \\
Não respondeu & 5 \\
Outras & 38 \\
\hline
\end{tabular}

Fonte: Questionário aplicado ao universo pesquisado. 
Se considerarmos que mais da metade do universo consome música, geralmente por meio de aparelhos com fones de ouvido, ao longo de quase todo o dia, podemos aventar que a música constitui quase uma trilha sonora que embala a realização de uma série de outras atividades - desde aquelas que exigem reflexão, como o estudo, até as que demandam socialização, como as conversas, as manifestações de amizade e companheirismo.

Outro dado importante diz respeito às canções consumidas. Os índices de preferência variam de acordo com a oferta do mercado fonográfico. As músicas e grupos preferidos em dado momento e consumido por um número significativo de adolescentes parece variar rapidamente. Em seis meses, os levantamentos revelaram uma variação relevante das preferências - o grupo Restart, Lady Gaga e Michel Teló revezaram-se como os artistas de músicas mais consumidas - , o que permite concluir que o gênero musical não constitui o fator mais importante a ser considerado para o consumo, mas a aceitação entre os pares.

Esse último aspecto revela um dado importante. A música parece cumprir, entre esses adolescentes, a mesma função indicada nos estudos anteriormente citados, relativos a outras regiões do país. Ela permeia os processos de socialização e de identificação. No entanto, ela guarda algumas distinções importantes: em primeiro lugar, permite entrever o significado que a condição de periferia assume em Belém para os adolescentes pesquisados; em segundo, a música cumpre a função de identificar o grupo etário e suas ramificações, mas não expressa, necessariamente, identificações de ordem social; em terceiro (e, por ora, último) lugar, ela viabiliza chaves para a compreensão do universo adolescente e das formas pelas quais o saber escolar é apropriado por ele.

\section{Sociabilidades e hierarquias}

Uma das hipóteses de que se partiu foi a de que o universo adolescente, fora do espaço escolar, expressaria não apenas os dilemas inerentes à faixa etária, mas os conflitos e questionamentos relativos à condição social. Buscava-se apurar, especialmente, as formas pelas quais os escolares expressavam sua condição de moradores de áreas periféricas, 
como concebiam as diferenças sociais, inerentes a uma sociedade marcada por uma distribuição desigual da riqueza, a leitura que faziam da cor e como se percebiam em relação a ela. A análise dos dados recolhidos permite considerar que o universo adolescente, fora dos centros urbanos mais estudados, pode guardar especificidades que exigem reflexão específica. Nesse sentido, a relação que os adolescentes estabelecem com a música é particularmente proveitosa.

O primeiro aspecto digno de nota foi a ausência de distinções de gosto, em função da condição socioeconômica dos entrevistados. O enriquecimento das classes ' $\mathrm{C}$ ' e ' $\mathrm{D}$ ', ocorrido nos últimos vinte anos, pode ser percebido no corpo discente da escola estudada, expresso no alto grau de utilização da rede mundial de computadores e de aparelhos para ouvir música. Apesar de tratar-se de uma escola privada, cuja mensalidade é de $1 / 2$ salário mínimo, verifica-se uma variação significativa dos patamares de renda, variação que, no entanto, não é percebida nos índices de gosto.

O segundo foi a ausência de músicas que denotassem ou conotassem as condições sociais próprias da periferia. A análise das letras das músicas indicadas como de maior consumo, ${ }^{34}$ independentemente do gênero (se pop, sertanejo ou tecnobrega), evidenciam letras que falam de amor, de relações amorosas e/ou de conotação sexual. Nenhuma das letras aponta formulações sobre as condições de vida, sobre exclusão social ou sobre o lugar de onde se fala. Mesmo se se considerar o tecnobrega ${ }^{35}$ um subgênero constituído a partir de um fenômeno musical paraense - o brega —, as letras das músicas não encaminham uma visão nativista.

O terceiro aspecto foi a diversidade dos padrões de consumo. Ao indicarem suas preferências, os adolescentes acabaram estabelecendo dois padrões: o consumo das que se pode chamar de "músicas do momento" era simultâneo à de outro grupo de músicas. Enquanto as pri-

\footnotetext{
34 Pop: "Te levo comigo" - Restart; "Razões e emoções" - Nx Zero. Sertanejo: "Meteoro", "Você não sabe o que é amor", "Sinais" - Luan Santana; "Fugidinha" - Michel Teló. Tecnobrega: "Brega do tupinambá" - Banda Amazonas; "Beba doida" - Banda Xeiro Verde.

35 Sobre o tecnobrega, ver Lydia Barros, "Tecnobrega, entre o apagamento e o culto", Revista Contemporânea, n. 12 (2009), pp. 62-79.
} 
meiras, executadas pelos artistas citados, tinham um apelo universal, outras músicas pareciam ser de consumo de grupos restritos. ${ }^{36}$

Como, no entanto, as respostas aos questionários não se mostraram suficientes para esclarecer inteiramente os três aspectos acima destacados, constituiu-se um grupo de discussão, ${ }^{37}$ reunindo doze adolescentes, para debater os dados que lhe seriam apresentados. Entre os doze alunos, a maioria se autoidentificou como parda (85\%) e os demais como pretos $(10 \%)$ ou brancos $(5 \%)$. Ao final do debate, reproduzimos as músicas indicadas como as preferidas pelo maior número de alunos e solicitamos que o grupo discorresse sobre cada uma delas. Os resultados foram surpreendentes.

Os adolescentes distinguem músicas para dançar e socializar com os amigos das músicas para ouvir e pensar. As músicas identificadas como as mais consumidas compõem o primeiro grupo, as de consumo restrito, o segundo. Isso pode parecer óbvio, mas esconde outras distinções. Os adolescentes reconheceram a existência de alguns grupos entre eles: os "nerds", os "populares", as "patricinhas" e os "malacos". Todos consomem as músicas mais tocadas que permitem a "curtição" e as associam aos momentos de socialização e diversão: dançar, "ficar" e rir. Os grupos, no entanto, apresentam comportamentos restritos, com reflexos no universo escolar. Os "nerds" e as "patricinhas" são considerados (e se consideram) estudiosos. Enquanto os primeiros gostam de rock, as segundas gostam de pop. Os "populares" transitam de um grupo a outro e, da mesma forma, consomem músicas sem restrição de gênero. Os "malacos" vivem no limite dos comportamentos aceitáveis, dentro e fora da escola — são associados à malandragem, à transgressão —, e consomem rap. ${ }^{38}$

\footnotetext{
36 "Realidade cruel", "Negro drama" - Os Racionais.

37 Utilizamos as indicações de Carla Beatriz Meinerz e Wivian Weller, "Grupos de discussão: uma opção metodológica na pesquisa em educação", Educação e Realidade, v. 36, n. 2 (2011), pp. 485-504; Wivian Weller, "Grupos de discussão na pesquisa com adolescentes e jovens: aportes teórico-metodológicos e análise de uma experiência com o método", Educação e Pesquisa, v. 32, n. 2 (2006), pp. 241-60.

${ }^{38}$ Sobre a expressão em perspectivas diferentes, cf.: Vinícius Gonçalves Bento da Silva e Cássia Baldini Soares, "As mensagens sobre drogas no rap: como sobreviver na periferia", Ciência \& Saúde Coletiva, v. 9, n. 4 (2009), pp. 975-85; Antonio Leandro da Silva, "Música rap: narrativa dos jovens da periferia de Teresina - PI", Imaginário, v. 12, n. 13 (2006), pp. 83-11; Zeni, "O negro drama do rap"; Hinkel e Maheirie, "Rap - Rimas afetivas da periferia"; Kehl, "Radicais, raciais, racionais".
} 
Esses são os grupos expressivos, os que se sobressaem em meio ao que os próprios adolescentes consideram como uma massa sem definições aparentes.

Instados a referir o que os identifica com os tipos de música de cada grupo, esboçaram-se as formas pelas quais os adolescentes compreendem o mundo e estabelecem uma hierarquia, dentro e fora da escola. As justificativas que apresentaram para a predileção por essa ou aquela música e para as formas de consumo - nas festas, nas baladas, entre os amigos, etc. - acabaram por esclarecer a relação que estabelecem com o mundo à sua volta e como o leem. A cor e os seus desdobramentos, finalmente, apareceram.

Das "patricinhas", de um lado, aos "malacos", do outro, constitui-se uma ordem social complexa. O consumo musical reflete essa ordem e suas escalas. O consumo das "músicas do momento" indica uma de suas dimensões - o fazer parte. Conhecer as músicas "do momento" é fundamental para o estabelecimento de sociabilidades ${ }^{39}$ para transitar nas festas e baladas, para ter o que falar com os colegas e, principalmente, para conseguir parceiros. Para "ficar" é importante saber dançar, saber cantar, reconhecer as músicas. Para o estabelecimento de cumplicidades, de relações de amizade e, sobretudo, de identificação, no entanto, as "do momento" não são determinantes.

Ante a solicitação de que indicassem os(as) cantores(as) das músicas "do momento" mais bonitos(as), eles deixaram perceber uma das facetas daquela hierarquia. A beleza foi um condicionante significativo para meninas e meninos. A despeito de não ser fundamental, ela foi considerada importante para ser aceito, ser considerado e para conseguir parceiros. Apesar de os alunos reunidos no grupo de discussão pertencerem aos "nerds", aos "populares" e às "patricinhas" e todos afirmarem curtir o tecnobrega nas baladas, nenhum deles associou a figura das cantoras daquele gênero à beleza. $\mathrm{O}$ mesmo ocorreu com

\footnotetext{
39 Claudia Pereira analisa as representações sociais sobre a juventude nos anúncios publicitários da revista Veja e constata que os valores que as constituem - modernidade, felicidade, sociabilidade e liberdade - passam a ser estratégicos na comunicação com todas as idades (Cláudia Pereira. "Juventude como conceito estratégico para a publicidade", Comunicação, Mídia e Consumo,v. 7, (2010), pp. 37-54).
} 
relação aos cantores dos grupos de hip hop, rap e pagode. Quando pedimos que explicitassem o que consideravam índices de beleza, dez dos doze alunos mencionaram a pele clara e o cabelo liso.

Instados a que aplicassem aqueles índices aos grupos que eles mesmos haviam identificado, rapidamente apontaram os "nerds" e as "patricinhas" como os grupos formados pelos mais bonitos, geralmente brancos e pardos, com predominância dos primeiros; o grupo dos "populares" se constituiria também de brancos e pardos, com predominância, porém, dos segundos; o grupo dos "malacos", por sua vez, de pretos e pardos. Ficou claro que os adolescentes compartilham uma visão hierárquica, expressa no valor e no lugar dos grupos e nos conceitos de beleza. Essa visão é compatível com um dos princípios da hierarquia da cor no Brasil, conforme ela é apresentada por diversos autores ${ }^{40}$ - na qual o branco e o negro representam os polos de um gradiente indicador do lugar social de cada um.

Essa hierarquia da cor se concretiza na escola, e dela decorre a leitura que os alunos fizeram do possível desempenho dos colegas. As noções de sucesso e desempenho, como ficou claro na discussão em grupo, estão associadas aos padrões de beleza e aos índices de cor quanto mais claro, maiores as possibilidades de sucesso dentro e fora da escola. Ela se concretiza, da mesma forma, na relação que estabelecem com a música: para dançar, para curtir, os gêneros e os artistas têm pouca importância, a batida, conforme definiram, é fundamental; para estabelecer identificações, para expressar ideias e sentimentos, no entanto, a imagem dos artistas tem quase o mesmo peso que as mensagens das letras e, em relação a isso, a hierarquia da cor é mais uma vez acionada.

As conclusões alcançadas até o momento sugerem desdobramentos. Em primeiro lugar, consolida-se a ideia de que as periferias merecem

\footnotetext{
40 Destacamos três trabalhos sugestivos: Jurandir Freire Costa, "Da cor ao corpo: a violência do racismo", in Neusa Santos Souza, Tornar-se negro (Rio de Janeiro: Graal, 1990), pp. 1-16; Nilma Lino Gomes, Sem perder a raiz: corpo e cabelo como símbolos da identidade negra, Belo Horizonte: Autêntica, 2008; Edith Piza e Fúlvia Rosemberg, "Cor nos censos brasileiros", Revista USP, n. 40 (1998/1999), pp. 122-37; Lilia Moritz Schwarcz, "Frágil democracia: na dança dos números" e "Nomes, cores e confusão", in Racismo no Brasil (São Paulo: Publifolha, 2001), pp. 51-64 e 65-74.
} 
estudos circunstanciados. Há um conjunto significativo de pesquisas voltadas para o que ocorre no Centro-Sul do país. Entender outras realidades é fundamental para se compreender a diversidade vivida nos limites do território. Aprofundar os estudos sobre o universo educacional amazônico é essencial para que essa diversidade seja compreendida.

Em segundo lugar, a presente investigação sugere um dado relevante: a quase inexistência de remissões à presença indígena na conformação do gradiente reconhecido. A região é demarcada por uma profunda interação com os povos indígenas, e o processo de conformação da sociedade amazônica, segundo a literatura especializada, decorre da relação - conflituosa ou fraterna - estabelecida com aqueles povos. ${ }^{41}$ O grupo estudado, todavia, desconhece essa relação e identifica como pardas pessoas de origens diversas - sem relação necessária com a origem étnica ou o fenótipo - , ponto esse que merece aprofundamento em estudos subsequentes.

Em terceiro lugar, firma-se a necessidade de aprofundar os estudos sobre o universo adolescente dentro e fora da escola, sendo conveniente apurar-se o que ocorre em escolas públicas em áreas de maior risco social, examinando-se o impacto que as condições socioeconômicas exercem no gosto e nas formas de identificação por meio da música. Torna-se cada vez mais forte a compreensão de que as questões que

${ }^{41}$ Ângela Domingues, Quando os índios eram vassalos: colonização e relações de poder no Norte do Brasil na segunda metade do século XVIII, Lisboa: Comissão Nacional para as Comemorações dos Descobrimentos Portugueses, 2000; Antônio Porro, O povo das águas: ensaios de etno-história amazônica, Rio de Janeiro: Vozes, 1995; Eduardo Viveiro Castro e Manuela Carneiro da Cunha (orgs.), Amazônia: etnologia e história indígena (São Paulo: Núcleo de História Indígena e do Indigenismo da USP/FAPESP, 1993); Francisco Jorge dos Santos, Além da conquista: guerras e rebeliões indígenas na Amazônia pombalina, Manaus: Editora da Universidade do Amazonas, 1999; John Hemming, Amazon Frontier: the Defeat of the Brazilian Indians, London: MacMillan, 1987; John Hemming, Red Gold: the Conquest of the Brazilian Indians, Cambridge, Massachusetts: Harvard University Press, 1978; José Ribamar Bessa Freire, Rio Babel: a história das línguas na Amazônia, Rio de Janeiro: EDUERJ/Atlântica, 2004; Leslie Robinson Anderson, "Following Curupira: Colonization and Migration in Pará, 1758 to 1930 as a Study in Settlement of the Humid Tropics" (Dissertation Doctorate of Philosophy in History, University of California, 1976); Nádia Farage, As muralhas dos sertões: os povos indígenas no Rio Branco e a colonização, Rio de Janeiro: Paz e Terra/ANPOCS, 1991; Patrícia Maria Melo Sampaio, Espelhos partidos: etnia, legislação e desigualdade na Colônia, Manaus: Editora da Universidade Federal do Amazonas, 2011; Leandro Tocantins, Amazônia: natureza, homem e tempo, Rio de Janeiro: Biblioteca do Exército, 1982. 
envolvem discriminação e preconceito exigem investigações que destaquem as formas sutis pelas quais uma e outro se manifestam.

Para muitos dos adolescentes investigados, nada do que afirmam, mesmo quando expressam seus ideais de beleza, tem qualquer relação com racismo, discriminação ou preconceito. $\mathrm{O}$ fato de associarem os "malacos" a determinada cor é uma constatação e não uma manifestação de preconceito, o que remete à nossa preocupação fundamental: os desdobramentos da educação para as relações étnico-raciais, instituídas pela Lei de Diretrizes e Bases da Educação, ${ }^{42}$ na desconstrução de uma visão hierárquica do mundo baseada na cor.

A pesquisa também ouviu professores, e, para muitos deles, a função principal da educação é "formar o cidadão crítico". Em nenhum momento, no entanto, eles associam essa formação à luta contra o preconceito. Para vários deles, "formar o cidadão crítico" é fortalecer o que consideram uma visão política "à esquerda". O racismo, o preconceito e as diversas formas de discriminação não são vistas como manifestações não cidadãs, o que não quer dizer que aprovem, sustentem ou ratifiquem o racismo. Longe disso. Quer dizer, isso sim, que não identificam esses vícios e desvios morais como um problema sobre o qual possam intervir por meio de ações pedagógicas concretas. Os dados recolhidos até o momento revelam que os alunos continuam reproduzindo um dos institutos mais cruéis de nossa cultura: o racismo à brasileira. ${ }^{43}$

No que tange à relação que estabelecem com os índices de cor, concluiu-se que o consumo musical daqueles adolescentes demarca uma

\footnotetext{
${ }^{42}$ Cf. legislação vigente: BRASIL, Lei no 9.394, 20 de dezembro de 1996. Lei de Diretrizes e Bases da Educação Nacional, Diário Oficial da União, 23/12/1996, Brasília, DF; BRASIL, Lei no 10.639, de 9 de janeiro de 2003, Diário Oficial da União, 10/01/2003, Brasília, DF; BRASIL, Ministério da Educação, Parecer CNE/CP $n^{0}$ 3/2004, Diretrizes Curriculares Nacionais para a Educação das Relações Étnico-Raciais e para o Ensino de História e Cultura Afro-Brasileira e Africana; BRASIL, Ministério da Educação, Plano nacional de implementação das diretrizes curriculares nacionais para a educação das relações étnico-raciais e para o ensino de história e cultura afro-brasileira e africana, 2010; BRASIL, Lei $\mathrm{n}^{\circ} 11.645$, de 10 de março de 2008 .

43 Telles, "Racismo à brasileira"; João Baptista Borges Pereira, "Racismo à brasileira", in Kabengele Munanga, Estratégias e políticas de combate à discriminação racial (São Paulo: EDUSP, 1996), pp. 75-94; Wilma N. B. Coelho, "O racismo à brasileira e a educação", Vida e Educação, n. 1, (2009), pp. 43-5.
} 
situação complexa, cuja compreensão demanda aprofundamento da reflexão. Se, por um lado, eles não restringem seu consumo musical a determinado gênero, por outro, associam alguns gêneros a determinados grupos de cor. Da mesma forma, se o consumo abrange um largo espectro de gêneros, artistas e ritmos, ele não impede a conformação de gostos que associam gêneros a grupos. Por fim, mas não menos importante, o consumo musical e as formulações dos alunos acerca de sua relação com a música demonstram que o saber axiológico, relativo a inclusão, diversidade e cidadania, não é necessariamente considerado no estabelecimento das sociabilidades juvenis.

Texto recebido em 7 de março de 2012 e aprovado em 2 de março de 2013

\begin{abstract}
Resumo
Este artigo aborda as formulações que adolescentes, alunos do ensino fundamental, elaboram sobre cor e preconceito, a partir da relação que estabelecem com as músicas que consomem. Nesse sentido, o consumo é visto como uma chave para a compreensão desse grupo etário e de uma das dimensões de sua vida: a leitura que fazem da hierarquia da cor e a forma como se percebem nela. Importa-nos, portanto, perscrutar de que forma a preferência manifestada por adolescentes que cursam o ensino fundamental permite entrever a relação que estabelecem com esse significante social brasileiro - a cor - e uma das relações estabelecidas com ele — o preconceito.

Palavras-chave: música - preconceito - adolescentes - hierarquia no ensino fundamental.
\end{abstract}

\begin{abstract}
This article discusses the formulations made by elementary school teenage students on color and prejudice, through the relation they establish with the music they listen. Thus, the consumption is seen as a key to understanding this age group and one of the dimensions of its life: the reading they make of the color hierarchy and how they perceive themselves in it. It is important, therefore, scrutinize how the preference expressed by teenagers who attend elementary school could allow an antecipatory glimpse of the relationship they establish with this Brazilian social significant - the color — and one of the relations established by it - prejudice.
\end{abstract}

Keywords: music - prejudice - teenagers - hierarch-elementary school. 
